\title{
DISTILASI BERTINGKAT BIOETANOL DARI BUAH MAJA (Aegle Marmelos L.)
}

\author{
Moh. Arif Batutah \\ Jurusan Teknik Mesin, FT- Universitas Muhammadiyah Surabaya \\ Email : arif.btth@gmail.com
}

\begin{abstract}
This research of bioethanol processed from fruit maja (Aegle Marmelos L.), the process consists of two stages of fermentation and ethanol fractional distillation for the separation of water with a temperature of 78 ${ }^{\circ} C$. The fermentation process 5-day produces ethanol content of $60 \%$ in the first distillation, fractional distillation is then performed to obtain the ethanol content above $90 \%$ and 4 times distilled into ethanol optimal levels above $90 \%$. This distillation produces ethanol content of $92 \%$. etonal content analysis results obtained $92.19 \%, \mu 1.498, \rho 0.8371,9546.223$ calorific value, flash point: +21 , pour point $60{ }^{\circ} \mathrm{C}$ not frozen and $\mathrm{PH} 5$.
\end{abstract}

Keywords: Fruit Maja, Fermentation, Distillation, Bioethanol

\begin{abstract}
ABSTRAK
Penelitian terkait proses bioethanol yang berasal dari buah Maja (Aegle Marmelos L.), memiliki dua tahap proses, yaitu fermentasi dan destilasi fraksi zat pada suhu $78^{\circ} \mathrm{C}$ untuk pemisahan kandungan ethanol dan air. Proses fermentasi 5 hari menghasilkan kadar etanol $60 \%$ pada distilasi pertama, kemudian dilakukan distilasi fraksional lanjutan untuk mendapatkan kandunan etanol diatas $90 \%$, dan dilanjutkan dengan destilasi empat kali untuk menghasilkan tingkat optimal etanol 90\%. Distilasi yang telah dilakukan, mampu menghasilkan kadar etanol 92\%. Hasil keseluruhan analisis kandungan etonal diperoleh 92,19\%, $\mu$ adalah 1.498, $\rho$ adalah 0.8371 , nilai kalor adalah 9546.223, flash point: +21 , pada titik suhu $60{ }^{\circ} \mathrm{C}$ tidak beku, dan PH 5 .
\end{abstract}

Keywords: Bioethanol, Buah Maja (Aegle Marmelos L), Distilasi, Fermentasi.

\section{PENDAHULUAN}

Energi mempunyai peranan penting yang sangat besar dalam kehidupan manusia di dunia. Dengan energi semua aktivitas manusia akan dapat berjalan lancar. Oleh karena itu, untuk mencukupi kebutuhan energi tersebut dalam beberapa abad terakhir, manusia telah berupaya untuk mencari dan memanfaatkan sumber-sumber energi yang ada di alam. Salah satu energi yang sering digunakan dalam aktivitas manusia adalah minyak bumi dan semua olahannya, seperti premium, solar, minyak tanah, dan lain-lain, kebutuhan energi dari bahan bakar minyak (BBM) di berbagai Negara di dunia dalam tahun terakhir ini mengalami peningkatan tajam. Tidak hanya pada negara negara maju, tetapi juga di negara berkembang seperti indonesia. Untuk mengantisipasi terjadinya krisis BBM pada masa yang akan datang, saat ini telah dikembangkan pemanfaatan bioethanol sebagai sumber energi terbarukan, contoh untuk pembuatan bioethanol dan gasohol.

Baru -baru ini pemerintah telah melaksanakan program kebijakannya yaitu konversi minyak tanah ke gas. Hal ini menandahi bahwa energi fosil sudah tidak layak lagi digunakan dimasa depan karena jumlahnya yang semakin sedikit dan dampaknya yang tidak ramah lingkungan. Gas buang yang ditimbulkan pada mesin- mesin kendaraan mengakibatkan terjadnya lubang pada lapisan ozon sehingga menyebabkan terjadinya pemaasan global. Kemudian masyarakat mulai beralih mencari energi alternatif yang murah dan ramah lingkungan sebagai penganti energi fosil. Bioethanol dihararapkan mampu mengantikan fungsi bahan bakar yang selama ini didominasi oleh bahan bakar fosil. Dari peneltian yang dilakukan oleh Musthohar (2012;55, disimpulkan bahwa bioethanol yang berbahan baku 1250 gr limbah jerami nangka menghasilkan kadar etanol sebesar 95,5\% sebanyak $250 \mathrm{ml}$. Penelitian yang serupa dilakukan oleh Listyowati (2012:50), disimpulkan bahwah bioethanol yang berbahan baku 750 gr biji mangga 
menghasilkan kadar etanol sebesar $94.28 \%$ sebanyak $250 \mathrm{ml}$. Dan pada penelitian ini akan mencoba membuat bioethanol yang serupa apakah dengan fermentasi dan dsetilasi bertingkat akan menghasilkan bioetanol dengan kadar lebih besar dari penelitian-peneltian sebelumnya.

\section{TINJAUAN PUSTAKA}

\section{Bioetanol}

Bioetanol $\left(\mathrm{C}_{2} \mathrm{H}_{5} \mathrm{OH}\right)$ adalah cairan biokimia dari proses fermentasi gula dari sumber karbohidrat mengunakan bantuan mikroorganisme. Bioetanol merupakan bahan bakar dari minyak nabati yang memiliki sifat menyerupai minyak premium. Untuk pengganti premium, terdapat alternatif gasohol yang merupakan campuran antara bensin dan bioetanol. Adapun manfaat pemakaian gasohol di indonesia yaitu : memperbesar basis sumber daya bahan bakar cair, mengurangi impor BBM, menguatakan security of supply bahan bakar meningkatkan kesempatan kerja, berpotensi untuk mengurangi ketimpangan pendapatan antara individu dan antar daerah, meningkatkan kemampuan nasional dalam teknologi pertaniaan dan industri, mengurangi kecenderungan pemanasan global dan pencemaran udara (bahan bakar ramah lingkungan) dan berpotensi mendorong eksopror komoditi baru.

\section{Standar Bioetanol}

Standar mutu merupakan pedoman untuk melakukan control bagi produsen dan sekaligus hak dari konsumen atas suatu produk yang dipakai. Produk biofuel baik sebagai bioetanol murni maupun campurannya dengan bensin yang dijual dipasaran harus memenuhi standar mutu bioetanol dan bensin yang berlaku di dalam negeri maupun di tingkat internasional. Standar bioetanol yang berlaku (berdasarkan spesifikasi premium) adalah mengacu kepada ASSTM (American Standart Testing of Materials). Diperlukan standar yang cocok dengan kondisi indonesia. Bioetahnol di indonesia diperoleh dari ubi kayu, ubi jalar, sagu, tebu, dan jagung dan lain-lain.

\section{Buah Maja}

Maja (aegle marmelos L.) Correa, suku jeruk-jerukan atau Rutaceae) adalah tumbuhan berbentuk pohon yang tahan lingkungan keras tetapi mudah luruh daunnya dan berasal dari daerah Asia tropika dan subtropika. Tanaman ini biasanya dibudidayakan di pekarangan tanpa perawatan dan dipanen buahnya. Maja masih berkerabat dekat dengan kawista. Di Bali dikenal sebagai bila. Di Pulau Jawa, maja sering kali dipertukarkan dengan berenuk, meskipun keduanya adalah jenis yang berbeda.

Tanaman ini mampu tumbuh dalam kondisi lingkungan yang bersuhu ekstrem; misalnya dari $49^{\circ} \mathrm{C}$ pada musim kemarau hingga $-7{ }^{\circ} \mathrm{C}$ pada musim dingin, pada ketinggian mencapai $+1.200 \mathrm{~m}$. Di Asia Tenggara, maja hanya dapat berbunga dan berbuah dengan baik jika musim kering dan tidak biasa dijumpai pada elevasi di atas $500 \mathrm{~m}$. Maja mampu beradaptasi di lahan berawa, di tanah kering, dan toleran terhadap tanah yang agak basa.

Warna kulit luar buah maja berwarna hijau tetapi isinya berwarna kuning atau jingga. Aroma buahnya harum dan cairannya manis tetapi rasa buah maja pahit.

\section{Fermentasi}

Fermentasi adalah proses produksi energi dalam sel keadaan anaerobik (tanpa oksigen). Secara umum, fermentasi adalah salah satu bentuk respirasi anaerobic, akan tetapi terdapat difenisi yang lebih jelas mendefinisikan fermentasi sebagai respirasi dalam ligkungan anaerobik dengan tanpa akseptor elektron eksterna. 
Proses fermentasi dimaksudkan untuk mengubah glukosa menjadi ethanol/bioethanol (alkohol) dengan mengunakan yeast. alkohol yang diperoleh dari proses fermentasi ini, biasanya alkohol dengan kadar 8 sampai 10 persen volume. Sementara itu, bila fermentasi tersebut digunakn bahan baku gula (molasses), proses pembuatan ethanol dapat lebih cepat.

Reaksi dalam fermentasi berbeda-beda tergantung pada jenis gula yang digunakan dan produk yang dihasilkan. Secara singkat, glukosa (C6H12O6) yang merupakan gula paling sederhana, melalui fermentasi akan menghasilkan ethanol $(2 \mathrm{C} 2 \mathrm{H} 5 \mathrm{OH})$.suhu medium fermentasi merupakan salah satu faktor yang paling penting dalam proses produksi ethanol. Saccharmyces cerevisae

$$
\mathrm{C}_{6} \mathrm{H}_{12} \mathrm{O}_{6} \rightarrow 2 \mathrm{C}_{2} \mathrm{H}_{5} \mathrm{OH}+2 \mathrm{CO}_{2}
$$

\section{Distilasi}

Destilasi adalah suatu metode pemisahan campuran yang didasarkan pada perbedaan tingkat volatilitas (kemudahan suatu zat untuk menguap) pada suhu dan tekanan tertentu. Destilasi merupakan proses fisika dan tidak terjadi adanya reaksi kimia selama proses berlangsung. Dalam penyulingan, campuran zat dididikan sehingga menguap, dan uanp ini kemudian didinginkan kembali ke dalam bentuk cairan. Zat yang memiliki titik didih lebih rendah akan menguap terlebih dahulu. Metode ini termasuk unit operasi kimia jenis perpindahan massa. Penerapan proses ini didasarkan pada teori bahwa pada suatu larutan. Masing-masing komponen akan menguap pada titik didinya (titik didih ethanol $78^{\circ} \mathrm{C}$ ).

Distilasi dilakukan untuk memisakan ethanol dari bear (sebagaian bear (sebagiaan besar adalah air dan ethanol). Titik didih ethanol murni adalah $78^{\circ} \mathrm{C}$, sedangkan air adalah $100^{\circ} \mathrm{C}$ (kondisi standar). Dengan memanaskan larutan pada suhu $78-100^{\circ} \mathrm{C}$ akan mengakibatkan sebagaian ethanol menguap, dan melalui unit kondensor akan bisa dihasilkan ethanol dengan konsentrasi 95\% volume.

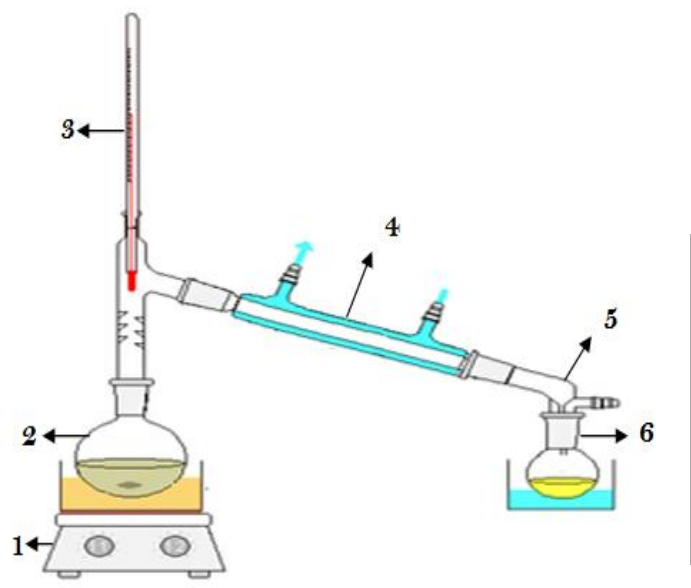

Keterangan :

1. Heater;

2. Gelas labu; Thermometer; Condensor Liebing;

3. Conentor;

4. gelas ukur.

Gambar 1. Alat Distilasi Sederhana

\section{Azeotrop}

Azeotrop merupakan campuran komponen pada komposisi tertentu dimana komposisi tersebut tidak bisa berubah hanya melalui distilasi biasa. Ketika campuran azeotrop dididihan, fasa uap yang dihasilkan memiliki komposisi yang sama dengan fasa cairnya. Campuran azeotrop ini sering disebut juga constant boiling mixture. 


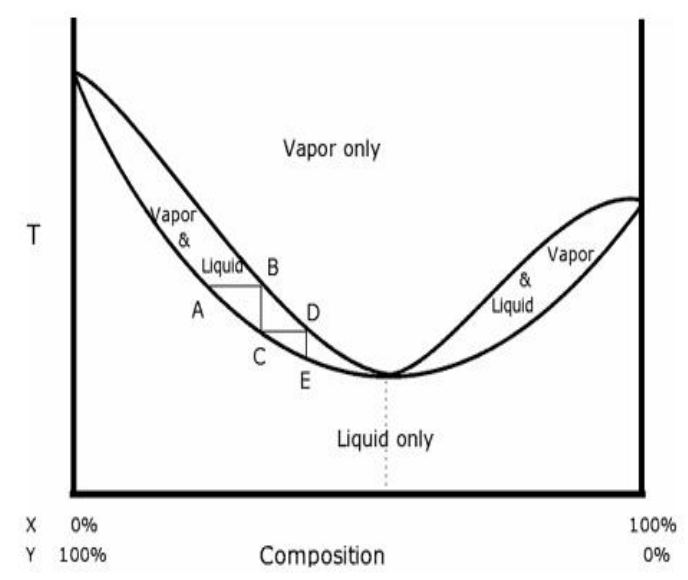

Gambar 2. Grafik azeotrop

Titik A pada pada kurva merupakan boiling point campuran pada kondisi sebelum mencapai azeotrop. Campuran kemudian dididihkan dan uapnya dipisahkan dari sistem kesetimbangan uap cair (titik B). Uap ini kemudian didinginkan dan terkondensasi (titik C). Kondensat kemudian dididihkan, didinginkan, dan seterusnya hingga mencapai titik azeotrop. Pada titik azeotrop, proses tidak dapat diteruskan karena komposisi campuran akan selalu tetap. Pada gambar di atas, titik azeotrop digambarkan sebagai pertemuan antara kurva saturated vapor dan saturated liquid. (ditandai dengan garis vertikal putus-putus).

\section{METODE}

Berikut diagram alir dalam penelitian.

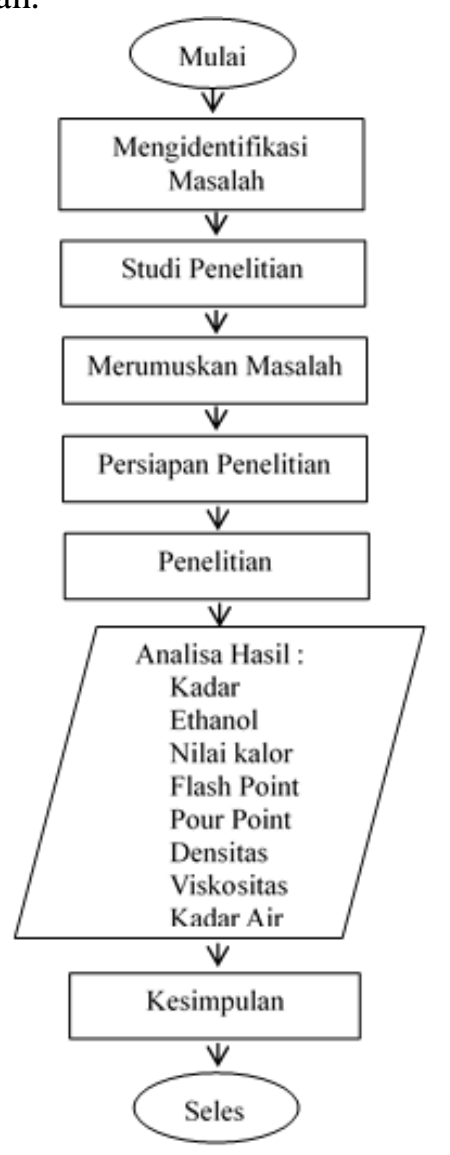




\section{Operasional Variabel}

Gambar 3. Flowchart Penelitian

Variable bebas pada penelitian ini adalah memvariasi jumlah perbandingan antara berat buah maja, air, ragi waktu fermentasi :

Tabel 1. Jumlah percobaan fermentasi

\begin{tabular}{cccc}
\hline Berat $($ gr $)$ & Air $(\mathrm{ml})$ & Ragi $(\mathrm{gr})$ & Waktu (hari) \\
\hline 250 & 500 & 5 & 5 \\
\hline 250 & 500 & 10 & 5 \\
\hline 250 & 500 & 15 & 5 \\
\hline 250 & 500 & 20 & 5 \\
\hline 250 & 500 & 25 & 5 \\
\hline
\end{tabular}

\section{Variabel Kontrol}

Variable kontrol dalam penelitian ini antara lain

a. Ragi fermentasi yang digunakan jenis ragi saccharomyces cerevisiae.

b. Berat buah maja proses fementasi adalah 250 gr.

c. Suhu proses fementasi adalah suhu ruangan/suhu kamar.

d. Suhu proses distilasi dibuat tetap maksimal yaitu $78^{\circ} \mathrm{C}$.

\section{Variabel Terikat}

Variabel terikat pada penelitian ini adalah persentase kadar Ethanol, Nilai kalor, Flash Point,Pour Point, Densitas, Viskositas, Kadar Air, dan PH.

\section{Teknik Pengumpulan Data}

Data yag diperlukan adalah komposisi buah maja, jumlah air dan ragi agar memperoleh ethanol dengan kadar yang maksimal. Setelah itu, baru dilakukan pengujian karakteristik dari bioethanol tersebut di laboratorium.

\section{Prosedur Kerja}

Pemisahan antara kulit luar dan daging buah, timbang daging buah seberat $250 \mathrm{gr}$, masukan kedalam blender di tambakan air murni seberat $500 \mathrm{ml}$, selanjutnya dileburkan sampai menjadi halus dan di tambahkan ragi, masukan kedalam jurigen berkapasitas 5 liter.

Proses diatas diulangi sampai menghasilkan beberapa sampel yang akan dilakukan analisa, sampel mana yang akan menghasilkan kadar ethanol tertinggi dengan perbandingan berat ragi 5, $10,15,20$ atau 25 gr pada proses fermentasi.

\section{Destilasi}

Proses yang dilakukan dalam pross distilasi ini adalah sebagai berikut :

a. Memasang thermocontrol pada kompor listrik untuk mengatur suhu

b. Menyiapkan labu distilasi dengan kapasitas $1000 \mathrm{ml}$ dan labu penampung hasil distilasi serta condesor liebing sebagai pendingin pada proses penguapa.

c. Hasil fermentasi dimasukan kedalam labu distilasi, kemudian proses distilasi dimulai dengan memanaskan pada suhu $78^{\circ} \mathrm{C}$ atau mengunakan titik didih alkohol.

d. Pengambilan data kadar ethanol dilakukan $50 \mathrm{ml}$ pertama hasil destilasi, kemudian dilakukan pengujian kadar ethanol mengunakan alcoholmeter. 
e. Untuk proses pengujian karakteristik bioethanol, maka proses destilasi harus mencapai kadar ethanol diatas $90 \%$.

f. Langkah destilasi kedua, langkah yang dilakukan hampir sama dengan destilasi pertama, namun ada sedikit tambahan yang boleh dilakukan agar kadar ethanol lebih maksimal, yaitu menambakan garam kedalam cairan dan silika gel ke dalam destilator. Silika gel yang dipasang pada condensor liebing berfungsi sebagai penyerap kelembaban air.

g. Proses destilasi selanjunya sama dengan prosess destilasi kedua sampai mengasilkan kadar ethanol diatas $90 \%$.

\section{HASIL DAN PEMBAHASAN}

Penelitaian telah dilakukan di laboratorium Bahan Bakar dan Pelumas Jurusan Teknik Mesin UNESA Surabaya dan analisa sepesifikasi ethanol dilakukan di Laboratorium Pertamina Lubricant dan Laboratorium Motor Bakar Teknik Mesin UB malang.

Tabel 2. Data Hasil Destilasi Ethanol

\begin{tabular}{cccccc}
\hline \multicolumn{3}{c}{ Perbandingan } & & Kadar Ethanol & Jmlh \\
Buah (gr) & Air (ml) & $\begin{array}{c}\text { waktu } \\
(\text { hari })\end{array}$ & Ragi $)$ & $\begin{array}{c}\text { Ka }) \\
(\mathrm{ml})\end{array}$ \\
\hline 250 & 500 & 5 & 5 & 20 & 100 \\
250 & 500 & 5 & 10 & 32 & 100 \\
250 & 500 & 5 & 15 & 45 & 100 \\
250 & 500 & 5 & 20 & 60 & 100 \\
250 & 500 & 5 & 25 & 55 & 100 \\
\hline
\end{tabular}

Berikut grafik kadar ethanol hasil dari proses fermentasi selama 5 hari dengan jumlah ragi yang berbeda - beda anatara $5-25$ gr.

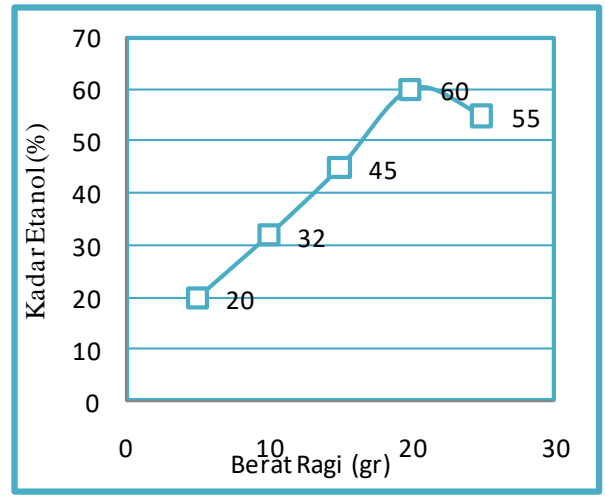

Gambar 4 Hasil Destilasi Dengan Parameter Berat Ragi

Berdasarkan tabel 2 dan gambar 4 di atas dapat terlihat bahwa untuk didapatkan hasil yang maksimal pada penambahan ragi tape 20 gr dan menurun pada penambahan ragi tape 25 gr. Semakin banyak ragi tape yang ditambahkan maka etanol yang dihasilkan juga semakin banyak karena dengan semakin banyak ragi yang ditambahkan, maka bakteri yang mengurai glukosa menjadi etanol pun semakin banyak tapi pada penambahan ragi 25 gr mengalami penurunan hal ini disebabkan adanya ragi yang mati pada saat proses fermentasi berlangsung, ini ditandai dengan ditemukannya serbuk putih kekuningan pada hasil akhir fermentasi sehingga mikroba yang berperan dalam fermentasi ini pun menjadi kurang maksimal, Adonan di dalam ragi tape bersifat amylolytic kuat dan menurunkan pangkat sebagian besar karbohidrat dari beras atau beras diuraikan ke dalam gula-gula yang sederhana yang lalu yang diuraikan lebih lanjut oleh ragi-ragi 
hingga mengandung alkoho, karena ragi merupakan komponen penting dalam proses fermentasi alkohol ini maka dengan berkurangnya jumlah ragi dalam media maka akan menurunkan konversi alkohol, sehingga menurunkan hasil.

\section{Hasil Pembuatan Ethanol Skala Besar}

Penelitian membutuhkan ehanol dari buah maja minimal $100 \mathrm{ml}$ dengan kadar ethanol diatas $90 \%$ untuk dapat dilakukan pengujian karakteristiknya. Dalam penelitian skala besar ini memerlukan 2000 gr buah maja, $4000 \mathrm{ml}$ dan massa ragi 160 gr dengan lama fermentasi 5 hari. Cairan yang dihasilkan kurang lebih $6000 \mathrm{ml}$, selanjutnya akan dilakukan proses destilasi I.

Tabel 3. Kadar Ethanol Hasil Destilasi Bertingkat

\begin{tabular}{ccc}
\hline Proses & $\begin{array}{c}\text { Jumlah ethanol } \\
\mathrm{ml}\end{array}$ & $\begin{array}{c}\text { Kadar ethanol } \\
\%\end{array}$ \\
\hline Destilasi 1 & 4550 & 60 \\
Destilasi 2 & 1580 & 73 \\
Destilasi 3 & 900 & 88 \\
Destilasi 4 & 530 & 92 \\
\hline
\end{tabular}

Proses detilasi menghasilkan $4550 \mathrm{ml}$ ethanol dengan kadar $60 \%$, pembuatan ethanol skala besar ini alat yang digunakan adalah alat detilasi yang berkapasitas 5 liter. Sedangkan untuk menaikan kadar ethanol dari $60 \%$ - $90 \%$ membutukan 3 kali atau lebih proses destilasi bertingkat dengan penambahan garam maupun silica gel. Berikut grafik kenaikan kadar ethanol dari hasil destilasi bertingkat

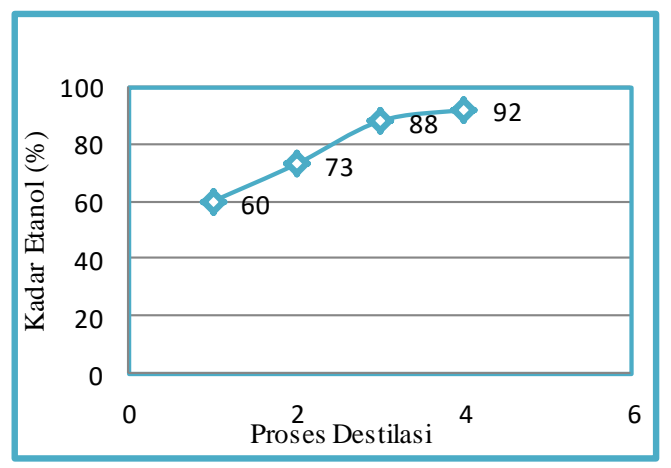

Gambar 5. Kenaikan Kadar Ethanol destilasi bertingkat

\section{Hasil Karateristik Bioethanol Dari Buah Maja}

Setelah mendapatkan ethanol dengan kadar $92 \%$, dilakukan uji karateristik dari bioethanol meliputi kadar ethanol, selanjutnya dilakukan uji karakteristik meliputi densitas, viskositas, flash point, pour point, kandungan air dan selanjutnya di Laboratorium Motor Bakar Fakultas Teknik Jurusan Mesin UB Malang meliputi nilai kalor dan PH, uji ini bertujuan untuk mengetahui kelayakan dari bioethanol digunakan sebagai bahan bakar, selanjutnya data tersebut akan di bandingkan dengan karakteristik dari bioethanol murni (kadar 99,4\%). 
Tabel 4. Sifat Ethanol Murni vs Ethanol Buah Maja

\begin{tabular}{lccl}
\hline \multicolumn{1}{c}{ Karateristik } & Ethanol murni & Ethanol dari Buah Maja & Satuan \\
\hline Kadar Ethanol & 99,4 & 92,19 & $\%$ \\
\hline Viskositas & 1,523 & 1,498 & $\mathrm{cST}$ \\
\hline Densitas & 0,789 & 0,837 & $\mathrm{gr} / \mathrm{cm}^{3}$ \\
\hline Flash Point & 12,77 & +21 & ${ }^{\circ} \mathrm{C}$ \\
\hline Pour Point & $--17,2$ & Sampai Titik $60{ }^{\circ} \mathrm{C}$ Tidak Beku & ${ }^{\circ} \mathrm{C}$ \\
\hline Kadar Air & - & 1410 & $\mathrm{Ppm}$ \\
\hline Nilai Kalori & 6380 & 9546,223 & $\mathrm{Kcal} / \mathrm{kg}$ \\
\hline PH & - & 5 & \\
\hline Sumber $:$ Physical & &
\end{tabular}

Sumber : Physical \& Theorecal Chemistry Lab. Safety Home. M. Farrich Mas'ud, 2010:54

Dari data diatas dapat disimpulkan bahwah bioethanol dari buah maja ini sudah dapat terbakar memiliki flash point dan juga dapat digunakan sebagai bahan bakar dari alam yang dapat diperbaharui dan dikembakangkan.

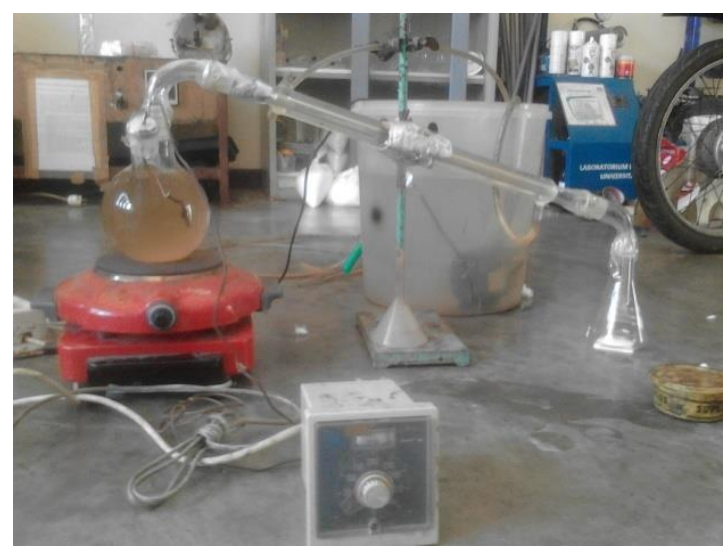

Gambar 6. Proses Destilasi

\section{KESIMPULAN}

Buah maja (Aegle Marmeos) sebagai bahan bakar dalam pembuatan ethanol ini yang didapat dari proses destilasi bertingkat sampai 4 kali untuk mencapai kadar ethanol yang optimal di atas $90 \%$. Destilasi keempat menghasilkan kadar ethanol $92 \%$. Ethanol dan air sangat susah dipisahkan, oleh sebab itu untuk pemisahan ethanol dan air harus dilakukan destilasi berulang kali . Hasil analisa yang diperolehadalah kadar 92,19 \%, $\mu$ 1,498, $\rho$ 0,8371, nilai kalor 9546,223, flash point +21 , pour point sampai titik $60^{\circ} \mathrm{C}$ tidak beku, kandungan air 1410 dan $\mathrm{PH} 5$.

\section{DAFTAR PUSTAKA}

[1] Demirbas A, "Biodiesel production from vegetable oils via catalitic and non-catalitic supercritical methanol transesterification methods," Progress in Energy and Combustion Science, Vol. 31 (2005) 466-487

[2] Alfena, (2008), "Produksi Etanol Menggunakan Zymomonas mobilis yang Dimutasi dengan Hidroksilamin", Skripsi, Jurusan Kimia, FMIPA, ITS, Surabaya.

[3] Budi, M dan Sasongko. (2007), “ Prospek Pengembangan UbiKayu Sebagai Bahan Baku Bioetanol Daerah Istimewa Yogyakarta.

[4] Venkanna B. K, Reddy, and C. Venkataramana, "Biodiesel Production and Optimization from Calophyllum Inophyllum Linn Oil (Honne Oil) - A Three Stage Method," Bioresource Technology, Vol. 100 (2009) 5122-5125. 
[5] Hanny, S. H., (2009), "Penentuan pH Optimum dalam Produksi Bioetanol dengan Menggunakan Zymomonasmobilis ATCC 19088", Skripsi, Fakultas Teknobiologi, Universitas Surabaya.

[6] Hardjono.A. (2001). Teknologi Minyak Bumi. Yogyakarta Gadjah Mada University Press.

[7] Rama Prihadana. Et la. 2007. Bioethanol Ubi Kayu Bahan Bakar Masa Depan Jakarta. PT Argo Media Pustaka.

[8] Rahman.A. (1992).Teknologi fermentai. Jakarta : Arcan

[9] Sri Utami Handayani. Pemanfaatan Bioethanol Sebagai Bahan Bakar Bensin. Fakultas Teknik Universitas Diponegoro

[10] Saroso, H., (1998), "Pemanfaatan Kulit Pisang dengan Cara Fermentasi untuk Pembuatan Alkohol"..

[11] Tamiang, Sri (2010). Penetapan kadar air metode destilasi Azeotrop.

[12] Timnasional Pengembangan BBN. (2007). Bahan Bakar Nabati/Bahan Bakar Alternatif dari Tumbuhan sebagai penganti Minyak Bumi dan Gas,- Cet.1.-Jakarta: Penebar Swadaya.

[13] Walisiewicz, M., 2003. Energi Alternatif :Panduan ke Masa Depan Teknologi Energi. Erlangga, Jakarta. 
Halaman ini sengaja dikosongkan 